\title{
Sorptive removal of ibuprofen from water using selected soil minerals and activated carbon
}

\author{
S. K. Behera $\cdot$ S. Y. Oh $\cdot$ H. S. Park
}

Received: 6 December 2010/Revised: 25 June 2011/Accepted: 8 September 2011/Published online: 23 November 2011 (c) CEERS, IAU 2011

\begin{abstract}
Pharmaceuticals have gained significant attention in recent years due to the environmental risks posed by their versatile application and occurrence in the natural aquatic environment. The transportation and distribution of pharmaceuticals in the environmental media mainly depends on their sorption behavior in soils, sediment-water systems and waste water treatment plants, which varies widely across pharmaceuticals. Sorption of ibuprofen, a non-steroidal anti-inflammatory drug, onto various soil minerals, viz., kaolinite, montmorillonite, goethite, and activated carbon, as a function of $\mathrm{pH}(3-11)$, ionic strength $(\mathrm{NaCl}$ concentration: $0.001-0.5 \mathrm{M})$, and the humic acid concentration $(0-1,000 \mathrm{mg} / \mathrm{L})$ was investigated through batch experiments. Experimental results showed that the sorption of ibuprofen onto all sorbents was highest at $\mathrm{pH} 3$, with highest sorption capacity for activated carbon $(28.5 \mathrm{mg} / \mathrm{g})$. Among the minerals, montmorillonite sorbed more ibuprofen than kaolinite and goethite, with sorption capacity increasing in the order goethite $(2.2 \mathrm{mg} / \mathrm{g})<$ kaolinite $(3.1 \mathrm{mg} / \mathrm{g})<$ montmorillonite $(6.1 \mathrm{mg} / \mathrm{g})$. The sorption capacity of the selected minerals increased with increase in ionic strength of the solution in acidic $\mathrm{pH}$ condition indicating that the effect of $\mathrm{pH}$ was predominant compared to that of ionic strength. An increase in humic acid concentration from low to high values made the sorption phenomena very complex in the soil minerals. Based on the experimental observations, montmorillonite, among the selected soil minerals, could
\end{abstract}

\section{S. K. Behera}

Center for Clean Technology and Resource Recycling,

University of Ulsan, Ulsan, South Korea

S. Y. Oh · H. S. Park $(\bowtie)$

Department of Civil and Environmental Engineering,

University of Ulsan, Ulsan, South Korea

e-mail: parkhs@ulsan.ac.kr serve as a good candidate to remove high concentrations of ibuprofen from aqueous solution.

Keywords Goethite $\cdot$ Kaolinite Montmorillonite Natural organic matter - Pharmaceuticals .

Point of zero charge $\cdot$ Sorption

\section{Introduction}

In recent years, pharmaceutical waste management has emerged as a critical aspect of environmental waste management practice, worldwide. According to the US EPA, the regulatory distinction between the hazardous waste and the medical waste has hampered a truly environmentally protective approach to the very complex issues surrounding pharmaceutical management. Pharmaceutical toxics are released into the water system, from many point and nonpoint sources. There is also a growing concern about the level of excreted pharmaceutical compounds from wastewater systems that may end up in the water supply (concentrations are usually $<1 \mu \mathrm{g} / \mathrm{L}$ ) as a parent compound or metabolite, and thus adversely affecting the human health and the environment (Behera et al. 2011; Daughton and Ternes 1999; Winker et al. 2008). Ibuprofen $\left(\mathrm{C}_{13} \mathrm{H}_{18} \mathrm{O}_{2}\right)$, also known as $\alpha$-methyl-4-(2-methylpropyl)-benzene acetic acid, is an antipyretic product and has been classified as a non-steroidal anti-inflammatory drug (NSAID). It is widely used in the treatment of rheumatic disorders, pain and fever (Mestre et al. 2007) and is one of the important drugs included in "Essential Drugs List" of World Health Organization, which results in its massive production worldwide (Heckmann et al. 2007). Table 1 illustrates the different physico-chemical properties of ibuprofen. Due to 
Table 1 Physico-chemical properties of ibuprofen

\begin{tabular}{llllll}
\hline CAS No. & Molecular structure & $\mathrm{MW}$ & $\log K_{\mathrm{ow}}$ & $\mathrm{p} K_{\mathrm{a}}$ & Water solubility (mg/L) \\
\hline $15687-27-1$ & & 206.3 & 3.97 & 4.91 & 21
\end{tabular}

Source Trenholm et al. (2006)

relatively low metabolism and absorption in the human body, most of the administered ibuprofen is excreted via feces and urine in the form of its parent compound or water-soluble metabolites and consequently released into the environment (Buser et al. 1999). Ibuprofen is slightly soluble in water, at neutral and acidic $\mathrm{pH}$, and on the other hand, it is readily soluble in organic solvents, and exhibits high mobility in the aquatic environment (Mestre et al. 2007). The presence of ibuprofen in the aquatic environment has been shown to inhibit the growth of duckweed Lemna minor at various concentrations ranging from $1 \mu \mathrm{g} / \mathrm{L}$ to $1 \mathrm{mg} / \mathrm{L}$ with the strongest effect observed at $1 \mathrm{mg} / \mathrm{L}$ (Pomati et al. 2004), and affect the reproduction of crustacean Daphnia magna at a minimum concentration of $13.4 \mathrm{mg} / \mathrm{L}$ (Heckmann et al. 2007). The conventional treatment practices in wastewater treatment plants are not usually designed to eliminate and/or degrade the pharmaceuticals. They can be partially eliminated in biological treatment systems, while majority of the non-treated pharmaceuticals tends to accumulate in large water bodies (Hernando et al. 2006). In this context, removal of ibuprofen from the water environment is considered important and requires improvised, yet cost-competitive technologies to ensure a sustainable natural environment.

Adsorption is a versatile treatment technique practiced widely for regulating mobility of chemical species and their geochemical cycles in the environment (Mohanty et al. 2006). Adsorption using activated carbon is ideal for removing small molecular organic compounds due to the availability of high surface area, and combination of welldeveloped pore structure and surface functional group properties (Dąbrowski et al. 2005; Li et al. 2002). Removal of several pharmaceuticals by activated carbon has been demonstrated (Behera et al. 2010; Synder et al. 2007; Ternes et al. 2002). The removal of ibuprofen from aqueous phase using commercially available activated carbon and activated carbon prepared from wastes such as cork and plastic have been reported in the literature (Melillo et al. 2004; Mestre et al. 2007, 2009). However, high cost and difficulty in regeneration of the activated carbon (Al-Futaisi et al. 2007; Chakraborty et al. 2005; Eren and Afsin 2007; Gürses et al. 2004) drive researchers to look for low cost materials having reasonable adsorption capacity as substitutes for activated carbon (Crini 2006; Gürses et al. 2004; Zohra et al. 2008). On the other hand, when natural attenuation of pharmaceuticals in soil is considered from a sustainability view point, inorganic soil components (clay minerals, iron/aluminum oxides etc) can play a synergistic role on the sorption phenomena (Sun et al. 2008). Clays and associated soil minerals have several advantages over other commercial-grade adsorbents; high adsorption capacity, non-toxicity, large potential for ion-exchange resulting from a net negative charge on the structure of the minerals, and colloidal dimensions to sorb different kind of molecules (Alkan et al. 2007; Babel and Opiso 2007; Parolo et al. 2008; Vimonses et al. 2009). Thus, pharmaceuticals like ibuprofen having single or multiple ionized groups are expected to interact strongly with inorganic soil components that are highly polar/ charged.

The fate and transport of pharmaceuticals in natural environment is usually governed by sorption reactions. The sorption and transport of ionizable compounds, e.g., ibuprofen, are strongly affected by the solution $\mathrm{pH}$. This is because the changing $\mathrm{pH}$ might cause protonation-deprotonation transition of the functional groups in ibuprofen molecule and sorbents, therefore influencing their mutual interactions and the sorption properties of ibuprofen. Similarly, the reactivity of both ibuprofen molecules and sorbents could be modified by the electronic screening effect as ionic strength changes. Besides, it has also been shown that the structural properties of organic solutes and humic acids (HA) exhibit combined effects on sorption characteristics (Sun et al. 2008).

In this study, the sorption of ibuprofen onto two major clay minerals (kaolinite and montmorillonite) and goethite, a hydrous iron oxide, commonly found in soil was assessed experimentally. In an effort to delineate the fate and transport of ibuprofen in the natural environment, sorption behavior of ibuprofen under various solution chemistry conditions viz., $\mathrm{pH}$, ionic strength and HA was compared using the batch sorption approach. Furthermore, the sorption capacities of the selected minerals were compared with that of activated carbon to justify the application of minerals as alternative sorbents for ibuprofen removal from aqueous phase. This research was performed in Ecosystems 
Laboratory, University of Ulsan, South Korea during March to July 2009.

\section{Materials and methods}

\section{Sorbents and their characterization}

The charcoal-based activated carbon in granular form (from DC Chemical Co. Ltd, Seoul, Korea) was washed and rinsed with distilled water to remove fines, dried at $105^{\circ} \mathrm{C}$ overnight and stored in a desiccator until use. Kaolinite (in the form of Kaolin) was obtained from Junsei Chemical Co., Japan and montmorillonite (in the form of Bentonite) was obtained from Yakuri Pure Chemicals Co., Japan. Goethite $(\alpha-\mathrm{FeOOH})$ particles were synthesized by reaction of $0.15 \mathrm{M} \mathrm{Fe}\left(\mathrm{NO}_{3}\right)_{3}$ with $2.5 \mathrm{M} \mathrm{KOH}$, following a previously reported procedure (Kosmulski et al. 2003). The precipitate was washed with $0.01 \mathrm{M} \mathrm{HNO}_{3}$ solution five times followed by washing with Milli-Q water three times. After centrifugation, the resulting material was dried at atmospheric temperature. The particle size analysis of activated carbon was performed by sieve analysis, as per ASTM standard specification, and those of kaolinite, montmorillonite and goethite was evaluated using a laser particle size analyzer (Malvern, mastersizer 2000). A Brunauer-Emmett-Teller (BET) surface analyzer (SA 3100, Beckman Coulter) was used to measure nitrogen adsorption at $77.3 \mathrm{~K}$ and the surface area of the sorbents was calculated from the isotherms using the BET equation. The surface morphology of all the sorbents was analyzed using scanning electron microscopy (SEM) (Hitachi Model S-2380 N, Tokyo, Japan). The determination of point of zero charge (PZC) of all sorbents was carried out by $\mathrm{pH}$ titration procedures (Faria et al. 2004).

Chemicals and sample preparation

Ibuprofen (99\%) was obtained from Sigma-Aldrich Co., St. Louis, MO, USA. Ibuprofen stocks were prepared by dissolving $100 \mathrm{mg}$ of ibuprofen in $100 \mathrm{ml}$ of HPLC grade methanol (SK Chemical, Ulsan, Korea), stored at $4^{\circ} \mathrm{C}$ and was used within a month of preparation. The sample solutions for all sorption tests were prepared by spiking the stock solution with $10 \%$ methanol (prepared with ultrapure water) to achieve the concentration levels of interest (Mestre et al. 2007). The fraction of non-ionized and ionized forms of ibuprofen as a function of $\mathrm{pH}$ will affect the sorption of ibuprofen to various sorbents. For a given $\mathrm{pH}$, the fraction of anionic ibuprofen $\left(\alpha_{1}\right)$ can be estimated by Eq. (1) (Schwarzenbach et al. 2003):
$\alpha_{1}=\frac{\left[A^{-}\right]}{C_{\mathrm{T}, \mathrm{A}}}=\frac{\left[A^{-}\right]}{[\mathrm{NA}]+\left[A^{-}\right]}=\frac{1}{1+\frac{1}{10^{\left(\mathrm{PH}-\mathrm{p} K_{\mathrm{a}}\right)}}}$

where $C_{\mathrm{T}, \mathrm{A}}=$ number of moles of species containing $\mathrm{A}$ (ibuprofen), $[\mathrm{NA}]=$ concentration of non-ionized ibuprofen, $\left[A^{-}\right]=$concentration of anionic ibuprofen. The fraction of non-ionic ibuprofen can also be estimated by the same manner as anionic fraction. HA stock solution was prepared by dissolving commercial $\mathrm{HA}$ in the form of sodium (HA, CAS: 68131-04-4, Aldrich, St. Louis, MO, USA) in ultra-pure water and stirred for about $24 \mathrm{~h}$. Then the solution was filtered through a $1.2-\mu \mathrm{m} \mathrm{GF/C} \mathrm{filter}$ (Whatman ${ }^{\circledR}$, England) to remove remaining particulate material (Ra et al. 2008). The solution was stored in dark at $4^{\circ} \mathrm{C}$ until use. The sample solutions containing HA were produced through diluting HA stock solution with ultrapure water. $\mathrm{NaCl}$ with a purity of $99.5 \%$ (DC Chemical Co. Ltd, Seoul, Korea) was used to make solutions of various ionic strengths. All chemicals were used without further purification.

\section{Batch sorption experiments}

Batch sorption experiments were conducted in a series of $100-\mathrm{mL}$ glass bottles containing $50 \mathrm{~mL}$ of $60 \mathrm{mg} / \mathrm{L}$ ibuprofen solution. Predetermined concentrations of sorbents $(1 \mathrm{~g} / \mathrm{L})$, were added to these bottles, fitted with Teflonlined rubber septa and were sealed airtight with aluminum caps. Preliminary tests showed no detectable sorption on these materials. All the experiments were performed in the dark in a thermostat controlled shaker (iNtRON Biotechnology Co. Ltd., Korea), maintained at $200 \mathrm{rpm}$ and a pre-set temperature of $25^{\circ} \mathrm{C}$. Based on the results from preliminary kinetic studies, stirring time of $6 \mathrm{~h}$ was selected as equilibrium time for all the sorbents. On completion of the sorption experiments with activated carbon, samples were filtered through $0.45-\mu \mathrm{m}$ membrane filters (Advantec, Pleasanton, CA, USA) to separate the activated carbon particles from the aqueous phase. During the sorption experiment with minerals, separation of the liquid from the solid phase was achieved by centrifugation at $5,000 \mathrm{rpm}$ for $10 \mathrm{~min}$, followed by filtration of the supernatant using $0.45-\mu \mathrm{m}$ membrane filters. Preliminary experiments showed no detectable retention in this filter type. The ibuprofen concentration in the filtrate was measured by a high performance liquid chromatography (HPLC) (Ultimate ${ }^{\circledR}$ 3000, Dionex, Sunnyville, CA, USA).

The amount of sorbed ibuprofen was calculated from the difference between the amount of ibuprofen initially added to the system and that remained in the solution after equilibration using Eq (2): 
$q_{\mathrm{e}}=\frac{\left(C_{0}-C_{\mathrm{e}}\right) V}{M}$

where $q_{\mathrm{e}}$ is the sorption capacity $(\mathrm{mg} / \mathrm{g}), C_{0}$ and $C_{\mathrm{e}}$ are the initial and equilibrium concentrations in the solution $(\mathrm{mg} / \mathrm{L})$, respectively, $V$ is the volume of the solution (L) and $M$ is the mass of sorbents $(\mathrm{g})$.

The effect of $\mathrm{pH}$ on ibuprofen sorption was also investigated in batch mode. The solutions were first prepared by diluting the stock solution using $10 \%$ methanol and the $\mathrm{pH}$ values (3-11) were adjusted using a few drops of $0.1 \mathrm{M}$ $\mathrm{HCl}$ or $\mathrm{NaOH}$. Ibuprofen concentration, sorbent dosage and the solution temperature were fixed at $60 \mathrm{mg} / \mathrm{L}, 1 \mathrm{~g} / \mathrm{L}$, and $25^{\circ} \mathrm{C}$, respectively. For ionic strength and $\mathrm{HA}$ effect studies, under similar experimental conditions, $\mathrm{NaCl}$ and HA concentrations were varied between $0.001-0.5 \mathrm{M}$ and $0-1,000 \mathrm{mg} / \mathrm{L}$, respectively. The concentration of HA was determined by a UV-Vis spectrophotometer (Shimadzu, model UVmini-1240, Japan) at a $\lambda_{\max }$ of $254 \mathrm{~nm}$ (Ra et al. 2008). All the experiments were carried out in duplicate and the mean values were reported. The relative errors of the data were within $5 \%$.

\section{Chemical analysis}

An HPLC system (Ultimate ${ }^{\circledR}$ 3000) (Dionex, Sunnyville, CA, USA) equipped with a Discovery ${ }^{\circledR}$ RP-Amide C-16 column $(150 \mathrm{~mm} \times 4.6 \mathrm{~mm}$ I.D., $5 \mu \mathrm{m})$ (Supelco, Bellefonte, PA, USA) and an UV-Vis detector was used to measure the ibuprofen concentrations at a detection wavelength of $230 \mathrm{~nm}$. The mobile phase used for elution was $25 \mathrm{mM} \mathrm{KH}_{2} \mathrm{PO}_{4}$ at $\mathrm{pH} 3.0(40 \%)$ and acetonitrile $(60 \%)$, delivered at $1 \mathrm{~mL} / \mathrm{min}$ through the column. A sample injection volume of $100 \mu \mathrm{L}$ was used. The column temperature was maintained at $30^{\circ} \mathrm{C}$. For quantification purpose, a calibration plot was performed within the range of experimental concentrations used [coefficient of determination $\left(R^{2}\right)$ greater than 0.99 ].

\section{Results and discussions}

\section{Sorbent characterization}

The physical properties and the surface morphology of sorbents influence the adsorption capacity. As a first step in characterization, the BET surface area of activated carbon and soil minerals was determined based on their nitrogen sorption isotherms. SEM technique was employed to observe the surface morphology of the sorbents. Figure 1 showed the SEM pictures of all sorbents. It can be seen from Fig. 1a that the external surface of activated carbon is full of cavities. The varieties of pores with different shapes could also be clearly identified from this micrograph, which accounts for the higher BET surface area of activated carbon (Table 2). In Fig. 1b, individual platelets of kaolinite are noticeable. Consequently, kaolinite clay had a smaller surface area. Montmorillonite showed its ordered and layered structure as observed from Fig. 1c. Goethite exhibited typical needle-type crystals as shown in Fig. 1d (Sparks 2003). The PZC of sorbents is a very important surface property and can be defined as the point where an adsorbent have zero potential charge on its surface. The presence of $\mathrm{H}^{+}$or $\mathrm{OH}^{-}$ions in solutions may change the potential surface charges of sorbents. If the solution $\mathrm{pH}$ is lower than the $\mathrm{pH}_{\mathrm{pzc}}$ of a sorbent, the surface functional groups on the sorbents will be protonated by the excess $\mathrm{H}^{+}$ ions; on the contrary if the solution $\mathrm{pH}$ is higher than the $\mathrm{pH}_{\mathrm{pzc}}$ of a sorbent, the surface functional groups on the sorbent will be deprotonated by the $\mathrm{OH}^{-}$ions present in the solution (Kubilay et al. 2007). The PZC, BET surface area, and particle size of all sorbents are shown in Table 2.

\section{Effect of $\mathrm{pH}$ on ibuprofen sorption}

The solution $\mathrm{pH}$ is a parameter of great interest in sorption processes in aqueous phase as it determines the charge of both the sorbent and the sorbate and thereby governs the sorbent-sorbate electrostatic interactions (Bautista-Toledo et al. 2005). Results showed the sorption capacity of activated carbon to be $28.5 \mathrm{mg} / \mathrm{g}$ at pH 3 (Fig. 2a). As pH was increased to 11 , sorption capacity gradually decreased reaching a value of $6.43 \mathrm{mg} / \mathrm{g}$. In terms of removal efficiency, it was $48 \%$ at $\mathrm{pH} 3$ and decreased to $11 \%$ at $\mathrm{pH} 11$. Similar result has been reported when powdered activated carbons made from cork waste were used for ibuprofen sorption from water. A removal efficiency of $90 \%$ was obtained between $\mathrm{pH} 2$ and 4, which decreased with increase in $\mathrm{pH}$ to 11 (Mestre et al. 2007). The sorption capacities of kaolinite, montmorillonite and goethite were $3.1,6.1$ and $2.2 \mathrm{mg} / \mathrm{g}$, respectively, at $\mathrm{pH} 3$ (Fig. 2b-d). However, sorption capacities of these minerals decreased dramatically to $0.4,2$ and $1 \mathrm{mg} / \mathrm{g}$, respectively, at a $\mathrm{pH}$ of 11. In terms of removal efficiencies, they were 6,12 and $4 \%$, respectively, for kaolinite, montmorillonite and goethite at $\mathrm{pH} 3$ and subsequently decreased to $0.8,3.7$ and $2 \%$ at $\mathrm{pH} 11$.

Changes in $\mathrm{pH}$ affected the dissociation of the ibuprofen molecule. According to the dissociation constant of ibuprofen $\left(\mathrm{p} K_{\mathrm{a}}=4.91\right)$, more than $50 \%$ of the ibuprofen is expected to be deprotonated at $\mathrm{pH}>\mathrm{p} K_{\mathrm{a}}$. Generally, an increase in the solution $\mathrm{pH}$ results in partially or fully deprotonated surface functional groups and thus a loss of positive charge and/or build up of negative charge (Wang et al. 2007). When sorption occurs above $\mathrm{pH} 9\left(\mathrm{pH}>\mathrm{p} K_{\mathrm{a}}\right)$, the anionic form of ibuprofen is dominant in solution and 

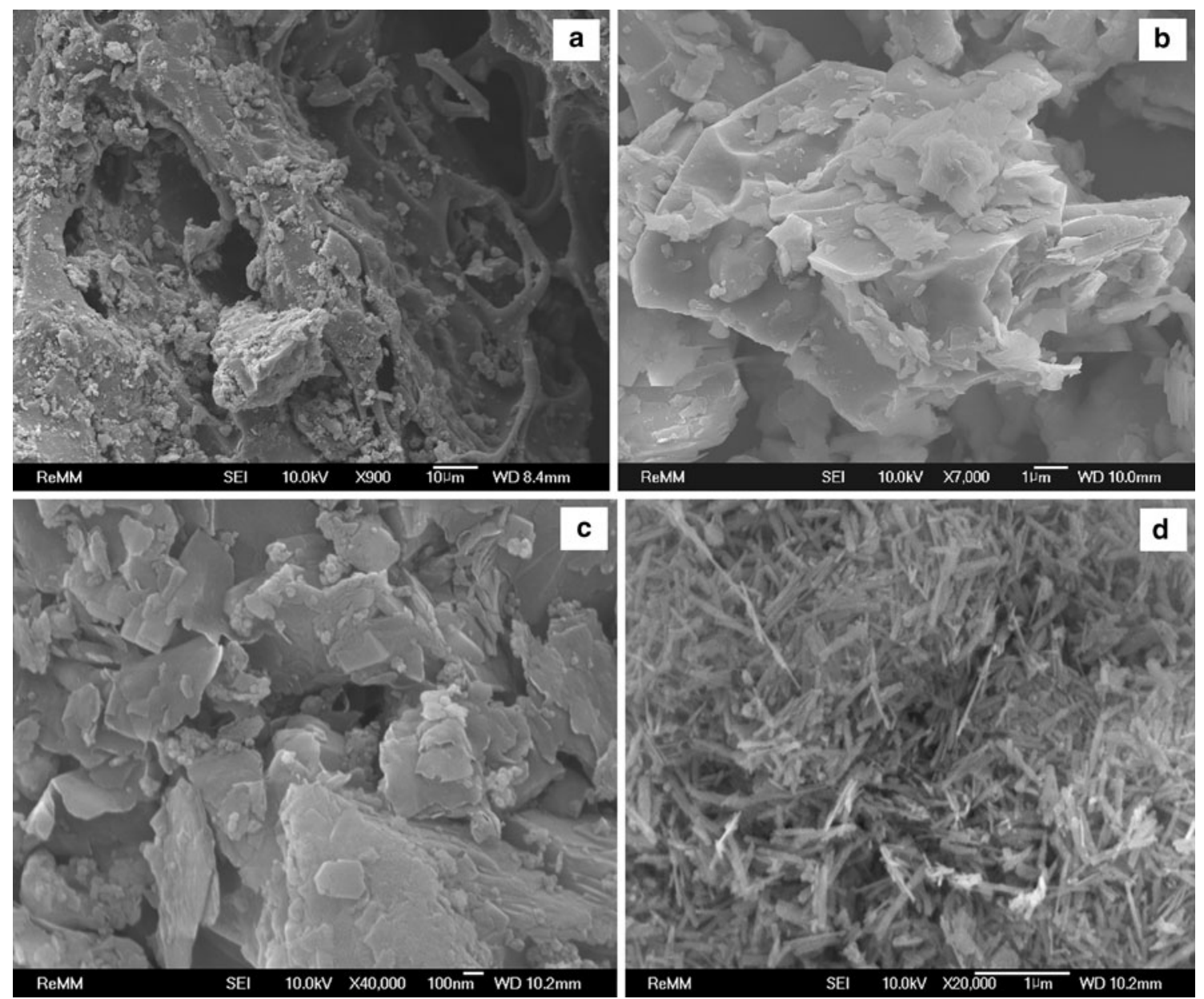

Fig. 1 SEM images of a activated carbon $(\times 900)$; b kaolinite $(\times 7,000)$; c montmorillonite $(\times 40,000)$; and d goethite $(\times 20,000)$

Table 2 Properties of sorbents

\begin{tabular}{lllll}
\hline Property & Activated carbon & Kaolinite & Montmorillonite & Goethite \\
\hline Average particle size & $1.5 \mathrm{~mm}$ & $6 \mu \mathrm{m}$ & $60 \mu \mathrm{m}$ & $28 \mu \mathrm{m}$ \\
BET surface area $\left(\mathrm{m}^{2} / \mathrm{g}\right)$ & 738.8 & 2.31 & 34.28 & 2.82 \\
PZC $^{\text {a }}$ & 6.88 & 4.13 & 2.15 & 6 \\
\hline
\end{tabular}

${ }^{a}$ Determined by the method mentioned in Faria et al. (2004)

additionally overall surface charge on the activated carbon is negative when the solution $\mathrm{pH}$ is greater than $\mathrm{pH}_{\mathrm{pzc}}$ (6.88). In this case, the sorption capacity is reduced due to electrostatic repulsion between the deprotonated ibuprofen and the negatively charged activated carbon surface. At acidic $\mathrm{pH}$, in contrast, the net charge on activated carbon surface is positive and ibuprofen is mainly non-dissociated. Thus, repulsive electrostatic interactions are minimized and sorption is enhanced. With respect to the minerals, as the surface functional groups are deprotonated at $\mathrm{pH}>5$ as indicated by the $\mathrm{pH}_{\mathrm{pzc}}$ of kaolinite (4.13), at $\mathrm{pH}>3$ as indicated by the $\mathrm{pH}_{\mathrm{pzc}}$ of montmorillonite (2.15), and at $\mathrm{pH}>6$ as indicated by the $\mathrm{pH}_{\mathrm{pzc}}$ of goethite (6), an enhanced electrostatic repulsion between negatively charged ibuprofen and the mineral surfaces is responsible for the dramatic reduction in ibuprofen sorption. Thus, as expected, ibuprofen sorption capacities of these minerals were decreased when solution $\mathrm{pH}$ was increased from strongly acidic to weakly alkaline conditions.

Furthermore, it is clear from the results that the extent of ibuprofen sorption onto kaolinite, montmorillonite and goethite is far less than that onto the activated carbon. This may be attributed to the open pore structure in activated carbon (Fig. 1) and lower surface areas of the minerals in comparison to activated carbon, aside from their likely variation in surface functional groups. The sorption edges 

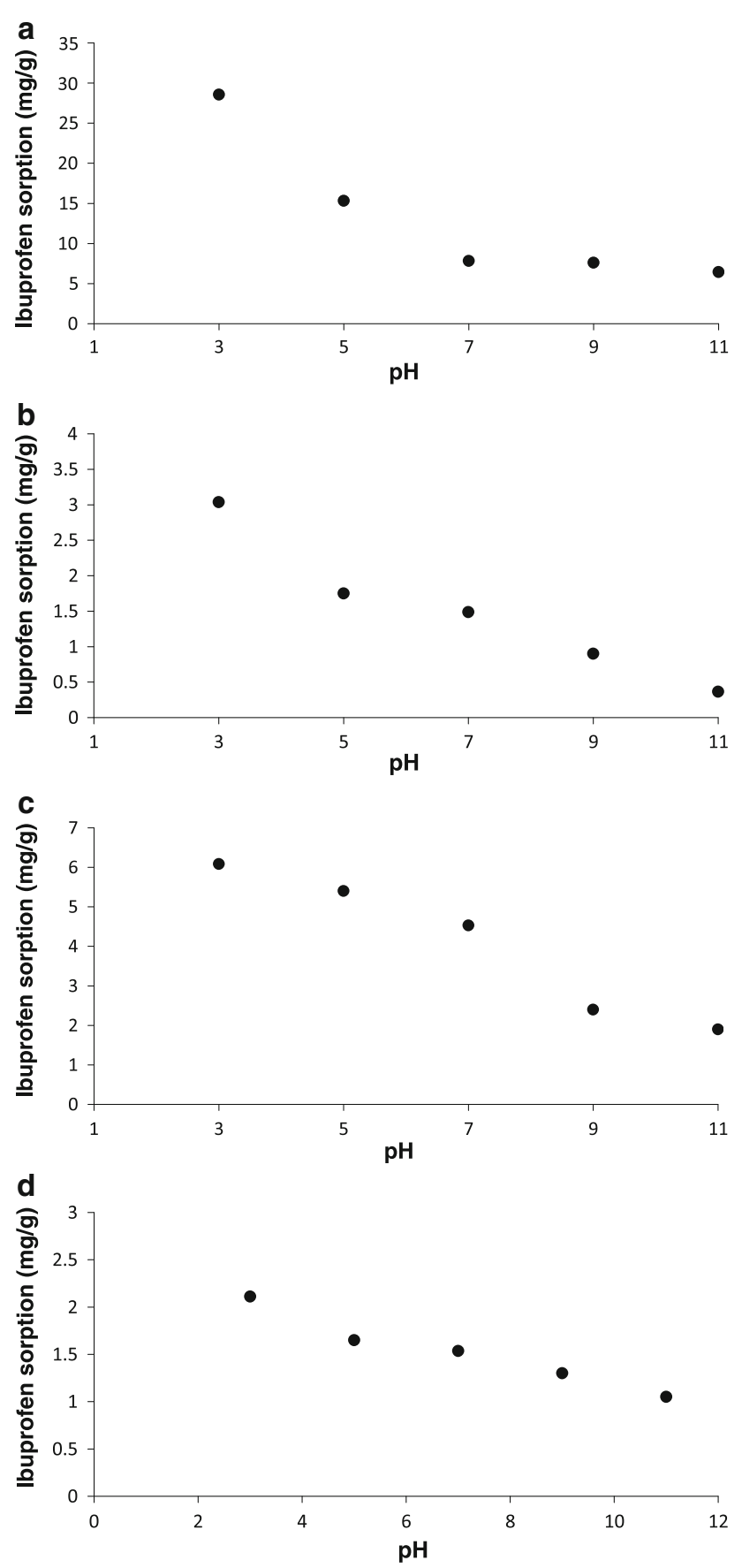

Fig. 2 Effect of solution $\mathrm{pH}$ on ibuprofen sorption onto a activated carbon, b kaolinite, $\mathbf{c}$ montmorillonite, and d goethite $\left(C_{0}=60 \mathrm{mg} / \mathrm{L}\right.$, sorbent dosage $=1 \mathrm{~g} / \mathrm{L}$ )

indicated a more favorable interaction of the fully protonated ibuprofen molecule with montmorillonite than kaolinite and goethite. Greater ibuprofen sorption to montmorillonite than to kaolinite and goethite was observed at all $\mathrm{pH}$ values. Particularly, at the neutral $\mathrm{pH}$ of 7 , montmorillonite had an ibuprofen sorption capacity of $60 \%$ while kaolinite and goethite had $20 \%$ sorption when compared to activated carbon, meaning that the ibuprofen sorption capacity of montmorillonite was three times that of kaolinite and goethite at $\mathrm{pH}$ 7. In the entire $\mathrm{pH}$ range of $3-11$, ibuprofen sorption capacity of montmorillonite was two to three times higher than kaolinite and goethite. This could be ascribed to the higher surface area $\left(34.28 \mathrm{~m}^{2} / \mathrm{g}\right)$ and organic matter content $(7.8 \%)$ of montmorillonite compared to those of kaolinite $\left(2.31 \mathrm{~m}^{2} / \mathrm{g}\right.$ and $3.1 \%$, respectively) and goethite $\left(2.82 \mathrm{~m}^{2} / \mathrm{g}\right.$ and $3.75 \%$, respectively). The differences in magnitude of ibuprofen interactions within these minerals indicate that mineral type must be considered when estimating ibuprofen interactions with clay mineral components. From practical application view point, montmorillonite, among soil minerals, seems to have good potential to remove higher amounts of ibuprofen from water at neutral $\mathrm{pH}$.

\section{Effect of ionic strength on ibuprofen sorption}

Ionic strength is an important factor in the study of aqueous-phase equilibrium. As shown in Fig. 3a, at pH 3, ibuprofen sorption onto activated carbon decreased from 32.5 to $24.1 \mathrm{mg} / \mathrm{g}$ with increase in ionic strength from $1 \times 10^{-3}$ to $1 \times 10^{-2} \mathrm{M}$. With further increase in ionic strength from $1 \times 10^{-2}$ to $5 \times 10^{-1} \mathrm{M}$ the sorption decreased from 24.1 to $20.35 \mathrm{mg} / \mathrm{g}$. Overall, there was a decrease by a factor of 1.6 in ibuprofen sorption with the increase in ionic strength from $1 \times 10^{-3}$ to $5 \times 10^{-1} \mathrm{M}$. It has been reported previously that electrostatic interactions may be reduced by increasing the ionic strength of the solution. This has the effect of screening that reduces all the electrostatic interactions, both attractive and repulsive (Stuart et al. 1991), which presumably explains the reason why increased ionic strength resulted in the decreased sorption of ibuprofen onto activated carbon.

From the investigation of the influence of ionic strength on ibuprofen sorption onto kaolinite, montmorillonite and goethite, it was observed that at $\mathrm{pH} \mathrm{3}$, there is almost no change in the sorption of ibuprofen onto the mineral surfaces up to an ionic strength of $5 \times 10^{-2} \mathrm{M}$ (Fig. 3b-d). However, with the increase in ionic strength from $5 \times 10^{-2}$ to $5 \times 10^{-1} \mathrm{M}$, there was an increase in the sorption of ibuprofen on to kaolinite (from 3.45 to $4.1 \mathrm{mg} / \mathrm{g}$ ), montmorillonite (from 6.81 to $12.05 \mathrm{mg} / \mathrm{g}$ ) and goethite (from 2.01 to $6.2 \mathrm{mg} / \mathrm{g}$ ). Theoretically, it is well known that sorbent particles and ibuprofen molecules are both surrounded by an electric double layer due to electrostatic interactions. Based on the Gouy-Chapman theory of the diffuse double layer, the thickness of the double layer is compressed by the increase in ionic strength of the solution (Rashid et al. 1972). At higher ionic strength, the sorption of ibuprofen will be high owing to the partial neutralization of the positive charge on the sorbent surface and a consequent compression of the electrical double layer by the chloride 


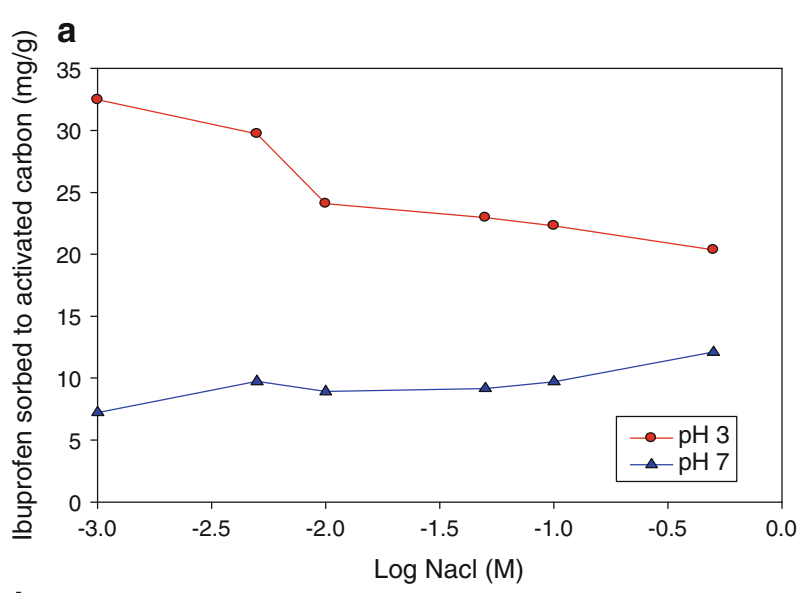

b
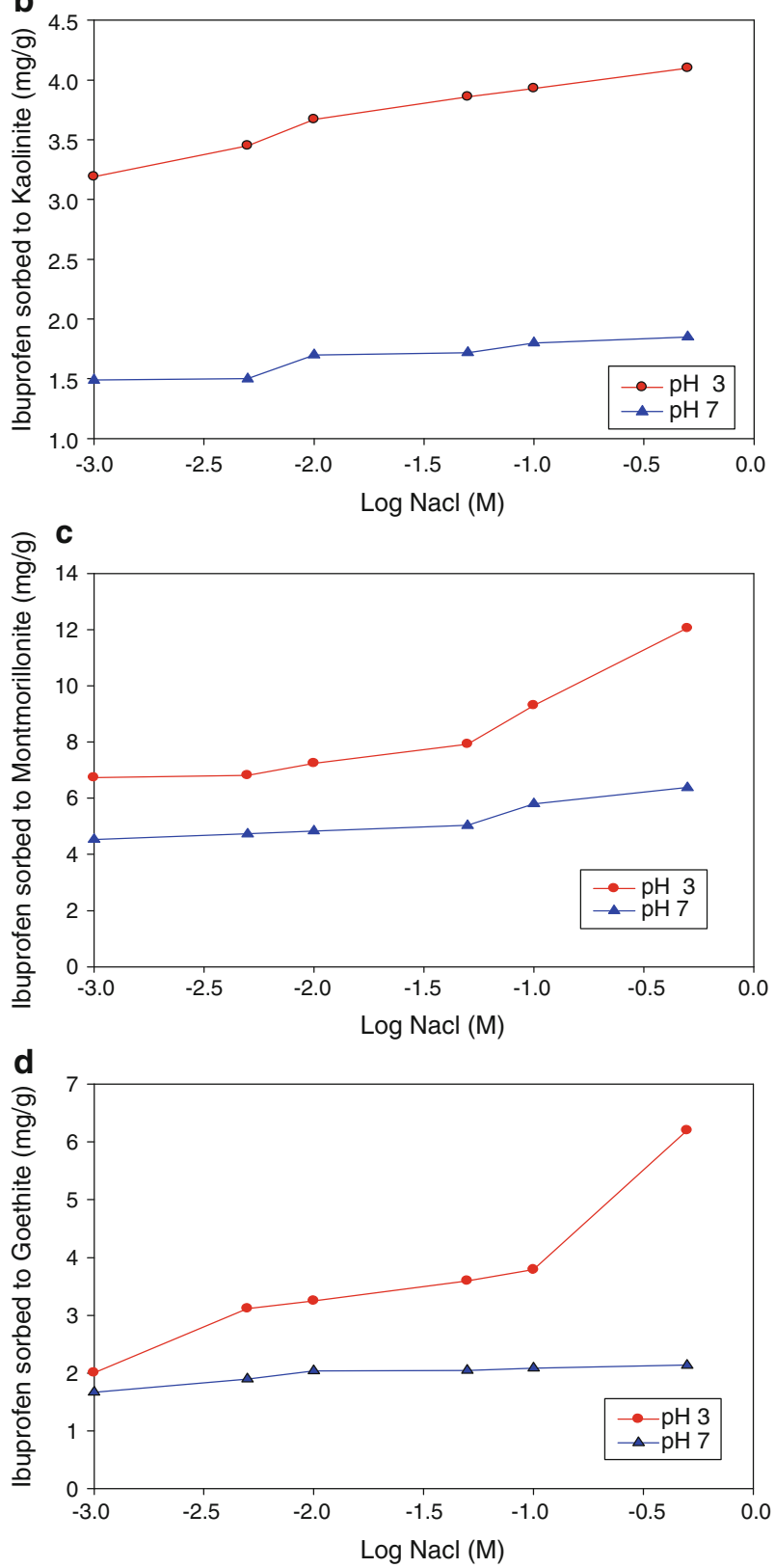

Fig. 3 Effect of ionic strength on ibuprofen sorption onto a activated carbon, b kaolinite, $\mathbf{c}$ montmorillonite, and d goethite $\left(C_{0}=60 \mathrm{mg} / \mathrm{L}\right.$, sorbent dosage $=1 \mathrm{~g} / \mathrm{L}, \mathrm{pH}=3$ and 7 )

ion. The chloride ion can also enhance the sorption of ibuprofen ion by pairing their charges, and hence reducing the repulsion between the ibuprofen molecules sorbed on the surface. This initiates the sorbent to sorb more positive ibuprofen ions. The increased sorption of ibuprofen onto mineral surfaces with increase in ionic strength could also be due to the decrease in solubility of ibuprofen in salt solution, commonly characterized as 'salting out' effect (Hurle and Freed 1972).

Irrespective of the increase in ionic strength, ibuprofen sorption onto all the sorbents was almost constant at $\mathrm{pH} 7$. However, at $\mathrm{pH} \mathrm{3}$, sorption of ibuprofen onto these sorbents increased significantly at higher ionic strengths. This indicates that at $\mathrm{pH} \mathrm{3}$, the effect of $\mathrm{pH}$ was predominant compared to the effect of ionic strength. Despite the increase in ionic strength, the constant sorption capacity at $\mathrm{pH} 7$ could be due to the fact that, at $\mathrm{pH} 7$ the anionic form of ibuprofen (99.2\%) is dominant in solution and the overall surface charge on all the sorbents is negative. This led to very high electrostatic repulsion between the deprotonated ibuprofen and the negatively charged sorbent surfaces, and was most likely to prevail over the effect of ionic strength at this $\mathrm{pH}$.

\section{Effect of HA on ibuprofen sorption}

To examine the effect of natural organic matter (NOM) on ibuprofen sorption, HA has been selected as a model of NOM since NOM comprises of $\sim 70 \%$ HA (Mamba et al. 2009). As depicted in Fig. 4a, ibuprofen sorption onto activated carbon decreased from 27.7 to $9.5 \mathrm{mg} / \mathrm{g}$, when the HA concentration was increased from 0 to $100 \mathrm{mg} / \mathrm{L}$. A further increase in $\mathrm{HA}$ concentration to $1,000 \mathrm{mg} / \mathrm{L}$ reduced the sorption capacity to $2.7 \mathrm{mg} / \mathrm{g}$. Overall, there was a net decrease in ibuprofen sorption by $25 \mathrm{mg} / \mathrm{g}$ with an increase in HA concentration up to $1,000 \mathrm{mg} / \mathrm{L}$. Though pore blockage and direct site competition are the most common mechanisms that would have affected activated carbon sorption in the presence of NOM, Ebie et al. (2001) suggested that pore blockage is the major contributing factor compared to the competitive adsorption effect between NOM and smaller target molecules.

At HA concentration up to $10 \mathrm{mg} / \mathrm{L}$, ibuprofen sorption onto kaolinite, montmorillonite and goethite decreased from 3.17 to $2.27 \mathrm{mg} / \mathrm{g}, 5.4$ to $1.4 \mathrm{mg} / \mathrm{g}$ and 2.2 to $1.5 \mathrm{mg} / \mathrm{g}$, respectively, (Fig. 4b-d) presumably due to instantaneous complexation of ibuprofen with HA in aqueous phase as HA was introduced (Ferreir et al. 2002; Gu et al. 2007). In the $10-50 \mathrm{mg} / \mathrm{L}$ HA concentration range, an increased 


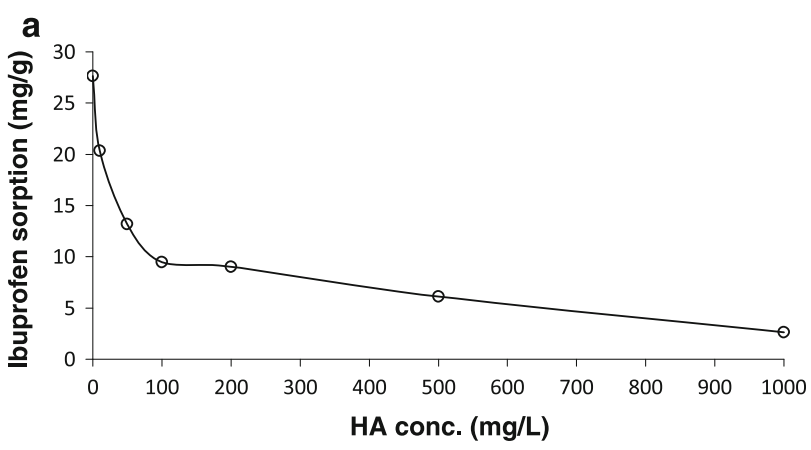

to (1) sorption of HA-complexed ibuprofen onto mineral surfaces and (2) sorption of free ibuprofen to HA sorbed to mineral surfaces. Control experiments showed that HA can be sorbed to all the mineral surfaces regardless of ibuprofen concentration (data not shown). As previously reported (Ra et al. 2008), it is clear that the increased amount of HA at mineral surfaces can result in enhancement of the sorption of pharmaceuticals via hydrophobicity. Additional experiments with HA-sorbed clays indicated that meaningful amount of ibuprofen can further be sorbed (data not shown). In contrast, the decreased ibuprofen sorption in the $50-100 \mathrm{mg} / \mathrm{L}$ HA concentration range (as in case of kaolinite and montmorillonite) and in the $50-200 \mathrm{mg} / \mathrm{L} \mathrm{HA}$ concentration range as in case of goethite may be explained by re-partitioning of ibuprofen between clay-associated HA and HA in the aqueous phase. With the increase of HA concentration in aqueous phase, the amount of HA-complexed ibuprofen is accordingly increased, which results in decreasing free ibuprofen in aqueous phase. Therefore, more ibuprofen could be desorbed from the clay surface (Kulshrestha et al. 2004).

Further increase in HA concentration from 100 to $1,000 \mathrm{mg} / \mathrm{L}$ (as in case of kaolinite and montmorillonite) and from 200 to $1,000 \mathrm{mg} / \mathrm{L}$ (as in case of goethite) increased the sorption of HA-complexed ibuprofen again to 6.66, 8.6 and $8.3 \mathrm{mg} / \mathrm{g}$ in kaolinite, montmorillonite and goethite, respectively. This increase was due to the fact that, with perturbations in the HA concentration range of 0-500 $\mathrm{mg} / \mathrm{L}$, sorption of HA onto the soil mineral surfaces increased very sharply when HA concentration was increased to $1,000 \mathrm{mg} / \mathrm{L}$. For instance, at HA concentration of $1,000 \mathrm{mg} / \mathrm{L}$, the maximum HA sorption by kaolinite, montmorillonite and goethite were $64,59.5$ and $10.5 \mathrm{mg} / \mathrm{g}$, respectively. Adsorption of HA onto silicate clays such as kaolinite and montmorillonite and metal oxide minerals such as goethite is well established (Schulthess and Huang 1991; Saito et al. 2004). Therefore, the HA-complexed ibuprofen was sorbed to the mineral surface as well as to HA associated with the mineral surfaces.

\section{Conclusion} b kaolinite, c montmorillonite, and d goethite $\left(C_{0}=60 \mathrm{mg} / \mathrm{L}\right.$, sorbent dosage $=1 \mathrm{~g} / \mathrm{L}, \mathrm{pH}=4.2$ )

ibuprofen sorption $(2.27-5.1,1.4-3.35$ and $1.5-4.7 \mathrm{mg} / \mathrm{g}$, respectively in kaolinite, montmorillonite and goethite) was observed, while a higher concentration of HA $(100 \mathrm{mg} / \mathrm{L})$ resulted in an opposite effect. This behavior is consistent with our previous investigation of triclosan sorption onto clay minerals (kaolinite and montmorillonite) in presence of HA (Behera et al. 2010). The increased sorption in the $10-50 \mathrm{mg} / \mathrm{L}$ HA concentration range is most probably due

Based on the experimental results of ibuprofen sorption onto various soil minerals and activated carbon, the following conclusions were drawn:

1. The sorption capacity of the soil minerals and activated carbon for ibuprofen removal was higher in acidic solutions than that in alkaline solutions.

2. At the neutral $\mathrm{pH}(\mathrm{pH}=7)$, the maximum percentage of ibuprofen removal by sorption onto activated carbon, kaolinite, montmorillonite and goethite were 
$13,3,9$, and 3\%, respectively. At this $\mathrm{pH}$, Montmorillonite, among the soil minerals tested under different conditions, showed comparable ibuprofen sorption capacity (60\%) to that of activated carbon, which has significance from practical application view point.

3. At lowest $\mathrm{pH}(\mathrm{pH}=3)$, the maximum percentage of ibuprofen removal by sorption onto activated carbon, kaolinite, montmorillonite and goethite were 48, 6, 12, and $4 \%$, respectively. The sorption capacity of the selected minerals at this $\mathrm{pH}$ increased with increase in the ionic strength of solution, which indicated the effect of $\mathrm{pH}$ to be predominant compared to that of ionic strength.

4. Removal of ibuprofen by activated carbon significantly reduced from 39.18 to $4.13 \%$ when the concentration of HA was increased from 0 to $1,000 \mathrm{mg} / \mathrm{L}$. On the contrary, removal by kaolinite, montmorillonite and goethite was increased from 2.5 to $4.35 \%, 4.3$ to $5.6 \%$ and 1.74 to $5.86 \%$, respectively with some perturbations in the sorption capacities within the studies range of HA concentrations. This kind of complex behavior could be attributed to the hydrophobicity of ibuprofen and affinity of HA towards ibuprofen than the soil minerals.

5. The information obtained from this study could help in providing relevant information on the transport and retention of ibuprofen in soil and subsurface environment. Further investigation may be warranted to understand the sorption behavior of ibuprofen present in wastewater at environmentally realistic concentrations.

Acknowledgments This research work was supported by University of Ulsan in South Korea. SKB thankfully acknowledges the Brain Korea-21 Post-Doctoral fellowship from the Ministry of Education, Science and Technology through the Environmental Engineering Program at the University of Ulsan.

\section{References}

Al-Futaisi A, Jamrah A, Al-Hanai R (2007) Aspects of cationic dye molecule adsorption to palygorskite. Desalination 214(1-3): 327-342

Alkan M, Demirbaş Ö, Doğan M (2007) Adsorption kinetics and thermodynamics of an anionic dye onto sepiolite. Microporous Mesoporous Mater 101(3):388-396

Babel S, Opiso EM (2007) Removal of Cr from synthetic wastewater by sorption into volcanic ash soil. Int $\mathbf{J}$ Environ Sci Technol 4(1):99-107

Bautista-Toledo I, Ferro-García MA, Rivera-Utrilla J, MorenoCastilla C, Vegas Fernández FJ (2005) Bisphenol a removal from water by activated carbon. Effects of carbon characteristics and solution chemistry. Environ Sci Technol 39(16):6246-6250

Behera SK, Oh SY, Park HS (2010) Sorption of triclosan onto activated carbon, kaolinite and montmorillonite: effects of $\mathrm{pH}$, ionic strength and humic acid. J Hazard Mater 179(1-3): 684-691
Behera SK, Kim HW, Oh JE, Park HS (2011) Occurrence and removal of antibiotics, hormones and several other pharmaceuticals in wastewater treatment plants of the largest industrial city of Korea. Sci Total Environ 409(20):4351-4360

Buser HR, Poiger T, Müller MD (1999) Occurrence and environmental behavior of the chiral pharmaceutical drug ibuprofen in surface waters and in wastewater. Environ Sci Technol 33(15):2529-2535

Chakraborty S, De S, DasGupta S, Basu JK (2005) Adsorption study for the removal of a basic dye: experimental and modeling. Chemosphere 58(8):1079-1086

Crini G (2006) Non-conventional low-cost adsorbents for dye removal: a review. Bioresource Technol 97(9):1061-1085

Dąbrowski A, Podkościelny P, Hubicki Z, Barczak M (2005) Adsorption of phenolic compounds by activated carbon: a critical review. Chemosphere 58(8):1049-1070

Daughton C, Ternes T (1999) Pharmaceuticals and personal care products in the environment: agents of subtle change? Environ Health Persp 107(Suppl 6):906-942

Ebie K, Li F, Azuma Y, Yuasa A, Hagishita T (2001) Pore distribution effect of activated carbon in adsorbing organic micropollutants from natural water. Water Res 35(1):167-179

Eren E, Afsin B (2007) Investigation of a basic dye adsorption from aqueous solution onto raw and pre-treated sepiolite surfaces. Dyes Pigments 73(2):162-167

Faria PCC, Órfão JJM, Pereira MFR (2004) Adsorption of anionic and cationic dyes on activated carbons with different surface chemistries. Water Res 38(8):2043-2052

Ferreir JA, Martin-Neto L, Vaz CM, Regitano JB (2002) Sorption interactions between imazaquin and a humic acid extracted from a typical Brazilian oxisol. J Environ Qual 31(5):1665-1670

Gu C, Karthikeyan KG, Sibley SD, Pedersen JA (2007) Complexation of the antibiotic tetracycline with humic acid. Chemosphere 66(8):1494-1501

Gürses A, Karaca S, Doğar Ç, Bayrak R, Açıkyıldız M, Yalçın M (2004) Determination of adsorptive properties of clay/water system: methylene blue sorption. J Colloid Interface Sci 269(2):310-314

Heckmann LH, Helen AC, Hooper L, Connon R, Hutchinson TH, Maund SJ, Sibly RM (2007) Chronic toxicity of ibuprofen to Daphnia magna: effects on life history traits and population dynamics. Toxicol Lett 172(3):137-145

Hernando MD, Mezcua M, Fernández-Alba AR, Barceló D (2006) Environmental risk assessment of pharmaceutical residues in wastewater effluents, surface waters and sediments. Talanta 69(2):334-342

Hurle KB, Freed VH (1972) Effect of electrolytes on the solubility of some 1,3,5-triazines and substituted ureas and their adsorption on soil. Weed Res 12(1):1-10

Kosmulski M, Maczka E, Jartych E, Rosenholm JB (2003) Synthesis and characterization of goethite and goethite-hematite composite: experimental study and literature survey. Adv Colloid Interface Sci 103(1):57-76

Kubilay Ş, Gürkan R, Savran A, Şahan T (2007) Removal of Cu(II), $\mathrm{Zn}$ (II) and $\mathrm{Co}(\mathrm{II})$ ions from aqueous solutions by adsorption onto natural bentonite. Adsorption 13(1):41-51

Kulshrestha P, Giese RF, Aga DS (2004) Investigating the molecular interactions of oxytetracycline in clay and organic matter: insights on factors affecting its mobility in soil. Environ Sci Technol 38(15):4097-4105

Li L, Quinlivan PA, Knappe DRU (2002) Effects of activated carbon surface and pore structure on the adsorption of organic contaminants from aqueous solution. Carbon 40(12):20852100

Mamba BB, Krause RW, Malefetse TJ, Sithole SP, Nkambule TI (2009) Humic acid as a model for natural organic matter (NOM) 
in the removal of odorants from water by cyclodextrin polyurethanes. Water SA 35(1):117-120

Melillo M, Gun'ko VM, Tennison SR, Mikhalovska LI, Phillips GJ, Davies JG (2004) Structural characteristics of activated carbons and ibuprofen adsorption affected by Bovine serum albumin. Langmuir 20(7):2837-2851

Mestre AS, Pires J, Nogueira JMF, Carvalho AP (2007) Activated carbons for the adsorption of ibuprofen. Carbon 45(10): 1979-1988

Mestre AS, Pires J, Nogueira JMF, Parra JB, Carvalho AP, Ania CO (2009) Waste-derived activated carbons for removal of ibuprofen from solution: role of surface chemistry and pore structure. Bioresour Technol 100(5):1720-1726

Mohanty K, Das D, Biswas MN (2006) Preparation and characterization of activated carbons from Sterculia alata nutshell by chemical activation with zinc chloride to remove phenol from wastewater. Adsorption 12(2):119-132

Parolo ME, Savini MC, Vallés JM, Baschini MT, Avena MJ (2008) Tetracycline adsorption on montmorillonite: $\mathrm{pH}$ and ionic strength effects. Appl Clay Sci 40(1-4):179-186

Pomati F, Netting AG, Calamari D, Neilan BA (2004) Effects of erythromycin and ibuprofen on the growth of Synechocystis sp. and Lemna minor. Aquat Toxicol 67(4):387-396

Ra JS, Oh SY, Lee BC, Kim SD (2008) The effect of suspended particles coated by humic acid on the toxicity of pharmaceuticals, estrogens, and phenolic compounds. Environ Int 34(2): 184-192

Rashid MA, Buckley DE, Robertson KR (1972) Interactions of a marine humic acid with clay minerals and natural sediment. Geoderma 8:11-27

Saito T, Koopal LK, Van Riemsdijk WH, Nagasaki S, Tanaka S (2004) Adsorption of humic acid on goethite: Isotherms, charge adjustments, and potential profiles. Langmuir 20(3):689-700

Schulthess CP, Huang CP (1991) Humic and fulvic acid adsorption by silicon and aluminum oxide surfaces on clay minerals. Soil Sci Soc Am J 55(1):34-42
Schwarzenbach RP, Gschwend PM, Imboden DM (2003) Environmental organic chemistry, 2nd edn. Wiley, New York, pp 253-254

Snyder SA, Adham S, Redding AM, Cannon FS, DeCarolis J, Oppenheimer J, Wert EC, Yoon Y (2007) Role of membranes and activated carbon in the removal of endocrine disruptors and pharmaceuticals. Desalination 202(1-3):156-181

Sparks DL (2003) Environmental soil chemistry, 2nd edn. Academic press, New York, p 60

Stuart MA, Fleer GJ, Lyklema J, Norde W, Scheutjens JMHM (1991) Adsorption of ions, polyelectrolytes, and proteins. Adv Colloid Interface Sci 34:477-535

Sun H, Zhu D, Mao JD (2008) Sorption of polar and nonpolar aromatic compounds to two humic acids with varied structural heterogeneity. Environ Toxicol Chem 27(12):2449-2456

Ternes TA, Meisenheimer M, Mcdowell D, Sacher F, Brauch H-J, Haist-Gulde B, Preuss G, Wilme U, Zulei-Seibert N (2002) Removal of pharmaceuticals during drinking water treatment. Environ Sci Technol 36(17):3855-3863

Trenholm RA, Vanderford BJ, Holady JC, Rexing DJ, Snyder SA (2006) Broad range analysis of endocrine disruptors and pharmaceuticals using gas chromatography and liquid chromatography tandem mass spectrometry. Chemosphere 65(11): 1990-1998

Vimonses V, Lei S, Jin B, Chow CWK, Saint C (2009) Adsorption of Congo red by three Australian kaolins. Appl Clay Sci 43(3-4): $465-472$

Wang SL, Tzoua YM, Lua YH, Sheng G (2007) Removal of 3-chlorophenol from water using rice-straw-based carbon. J Hazard Mater 147(1-2):313-318

Winker M, Faika D, Gulyas H, Otterpohl RA (2008) A comparison of human pharmaceutical concentrations in raw municipal wastewater and yellow water. Sci Total Environ 399(1-3):96-104

Zohra B, Aicha K, Fatima S, Nourredine B, Zoubir D (2008) Adsorption of Direct Red 2 on bentonite modified by cetyltrimethylammonium bromide. Chem Eng J 136(2-3):295-305 